\title{
HVAC Corona Current Characteristics and Audible Noise during Rain
}

\section{Journal Article}

Author(s):

Xu, Pengfei; Hedtke, Sören (D); Zhang, Bo; Pfeiffer, Martin D.; Franck, Christian (D); He, Jinliang

Publication date:

2021-02

Permanent link:

https://doi.org/10.3929/ethz-b-000428503

Rights / license:

In Copyright - Non-Commercial Use Permitted

Originally published in:

IEEE Transactions on Power Delivery 36(1), https://doi.org/10.1109/tpwrd.2020.2975803 


\section{(C) 2020 IEEE.}

Personal use of this material is permitted. Permission from IEEE must be obtained for all other uses, in any current or future media, including reprinting/republishing this material for advertising or promotional purposes, creating new collective works, for resale or redistribution to servers or lists, or reuse of any copyrighted component of this work in other works."

Digital Object Identifier: 10.1109/TPWRD.2020.2975803 


\title{
HVAC Corona Current Characteristics and Audible Noise during Rain
}

\author{
Pengfei Xu, Sören Hedtke, Bo Zhang, Martin Pfeiffer, Christian M. Franck, Jinliang He
}

\begin{abstract}
Corona Audible Noise is a major factor regarding the public acceptance of overhead lines. In this paper, 2-conductor bundle is used to study the influence of rain on AC corona discharge. Rainfall is simulated by a large rain dispenser, which can be adjusted over a wide range. Using this experimental setup, the transient AC audible noise and corona current pulse characteristics under rainfall condition were studied.

It was found that there are three different stages of audible noise level during rain, in which the audible noise level during the steady state stage is the highest. This transient characteristic could be explained by two different types of corona discharges for discharges above and below the conductor.

Furthermore, the steady state audible noise level was studied under a wide range of rain rates and applied surface electric fields. It was found that the sensitivity of the audible noise level to the rain rate decreases with the applied electric field. This finding is of vital importance as the rain intensity is regarded as one of the most important factors influencing the HVAC audible noise, and a higher rain rate is usually considered to cause a higher audible noise level. A possible explanation of this phenomenon is attributed to the effect of a "critical number of corona sources", which is well known from DC corona and possible evidence is provided based on long-exposure photos.
\end{abstract}

Index Terms - Corona, HVAC, Rain, Audible noise

\section{INTRODUCTION}

$\mathrm{T}$ HE corona performance, especially with regard to audible noise (AN) and the impact on human health, is a main factor influencing public acceptance of overhead line projects [1]. While corona typically does not occur on dry and clean conductors, the electric field on the conductor surface (surface gradient) can exceed the corona onset due to field enhancements, such as water drops [2]. In this case, the ionization of air will cause a corona current pulse and the generated heat energy will cause a pressure difference audible as an acoustic impulse [3]. Due to the high number of corona sources, the audible noise will cause a broadband hissing or crackling audible noise [4]. Furthermore, the oscillation of the generated ion cloud in an alternating AC field will cause an additional humming noise component of double the grid frequency, which does not occur in DC systems [5].

Based on a large number of outdoor test lines, several empirical formulas have been derived by various institutes to predict the audible noise in rainy conditions [6]. While many

This work was financially supported by the National Natural Science Foundations of China under Grant Nos. 51237004 and 51322703, National Research Program 'Energy Turnaround' (NRP 70) of the Swiss National Science Foundation (SNSF), as well as by the German TSO TransnetBW GmbH. of these formulas differ between wet conductor conditions and heavy rain [7], only the formula derived by EPRI gives a correction term for the rain intensity [3]. Still, several studies show a clear increase of the audible noise with rain intensity [8]-[11]. However, only a very small number of researchers have investigated the impact of rain intensity with regard to the applied voltage and surface gradient [9], [10].

As right of way are difficult to obtain in most areas of Europe, the number of existing overhead lines to be converted or uprated is strongly increasing. A recent case study has demonstrated that such a voltage increase obviously leads to higher than usual surface gradients in case the tower statics do not allow for significantly bigger bundles [12]. As most empirical formulas extrapolate outside of the range of the measured values for this case, this can cause significant deviations between different prediction methods and measurements. In consequence, this paper will study the audible noise for an increased range of electrical fields in order to better understand these phenomena and improve prediction formulas including high surface gradients.

Furthermore, most of the existing data was derived from outdoor experiments with typically highly fluctuating rain intensities. However, previous studies have shown that the corona performance will indeed not be constant, but vary over time during transient rain periods [4], [13], [14]. A very important factor for this is the deformation of the water drops in an electric field, with different corona source geometries causing very different corona characteristics [4], [15], [16]. With an application of a sufficiently high electric field, the water drops will form a spike-shaped Taylor cone with a very high electric field at the tip [17], typically causing lower audible noise due to high frequent hissing corona with a high repetition rate, loss current and space charge density, but low amplitude [4], [16]. Therefore, the reason for the decrease of audible noise in rain for HVDC is generally attributed to the shielding effect of these space charges [13], [18], while the DC corona current increases with rain intensity [19].

Besides, it was shown previously [13] that in the first minutes after rain onset, DC discharges can occur from small undeformed drops on the upper side of the conductor, causing strong corona pulses of low repetition rate. These discharges will however vanish with the increasing amount of water on the conductor, which then allows big water drops

P. Xu, B. Zhang and J. He are with the State Key Lab of Power System, Department of Electrical Engineering, Tsinghua University, Beijing 100084, China (shizbcn@tsinghua.edu.cn)

S. Hedtke, M. Pfeiffer and C. M. Franck are with the High Voltage Laboratory (HVL) of ETH Zurich, Switzerland (franck@eeh.ee.ethz.ch) 
and the formation of Taylor cones.

For AC corona, recent studies of the authors have found different possible mechanisms based on a scaled single-drop line to ground setup using high-speed footage. This difference is found to be closely related to the altered response of the water drop under the influence of AC and DC electric field [20], [21]. Under rainfall condition, DC corona discharge is mainly caused by Taylor cone deformation [13]. Generally, the stability of water drops on the conductor surface decreases with the increase of rain rate [20], [21]. Thus, a higher rain rate contributes to lower DC audible noise due to an increase in the ionic space charge, shielding the conductor as well as the instability of the Taylor cone [20]. As demonstrated in a recent publication of some of the authors [21], the oscillation of water droplets under AC electric field weakens the stability of Taylor cone formation, and there are two kinds of corona discharge occurring instead Firstly, for the so-called "dripping" discharge, a gap discharge will occur on the upper side when raindrops dripping on the conductor. Secondly, the introduced "crashing" discharge can occur on the lower side from small drops leaving the conductor, in which the small drops are generated by the breaking process with the vibration of the drops on conductors. Furthermore, both these types have shown to increase with the rain rate under certain electric fields. As a result, the AC corona performance gets worse with the increase of rain rate [21].

Due to these explained uncertainties regarding the effect of rain rate on the $\mathrm{AC}$ corona performance, this study will investigate the transient AC corona characteristics during periods of constant rain for different rain intensities in a larger laboratory setup as described in [13]. Furthermore, also the corona current pulses, which are known to have a strong correlation with the audible noise [22], are captured to explain the observed audible noise behavior. The results are then compared to previous results and discussed based on the introduced corona types in [21].

\section{EXPERIMENTAL SETUP}

The experimental setup and procedure were described in detail in [13] and only a few key aspects will be described here. As shown in Fig. 1, an AC voltage was applied to a $6.8 \mathrm{~m}$ long double bundle with the widely used ACSR 265/35 conductors suspended $2.65 \mathrm{~m}$ above ground (lowest point, sag $10 \mathrm{~cm}$ ) in an indoor laboratory. The conductors were parallel to the ground and the bundle spacing between these two conductors was $40 \mathrm{~cm}$. The AC voltage supply can be adjusted from $0 \sim 400 \mathrm{kV}$ (RMS). The measured experimental parameters were AC voltage, AC corona current waveform, A-weighted sound pressure level (SPL), and videos recorded through a UV corona scope. The audible noise was measured with a Norsonic Nor118 Class1 sound level meter, as well as the respective one-third octave bands. The microphone was aimed at the mid-span in $4.47 \mathrm{~m}$ distance to the bundle at the height of maximum sag. Prior to every experiment, the conductors were cleaned with lint-free ethanol wipes. Besides, the dry and clean conductors were subjected to the test voltage for 30 min to remove remaining particles, after which the dry test for 10 min was launched and then the rain was switched "on". After 120 min of precipitation, the rain was stopped again. To ensure a clear start and end of the rain period, an overhead travelling crane with an additional rain reservoir was placed below the rain simulator. The rain rate can be adjusted from $0.2 \mathrm{~mm} / \mathrm{h}$ to $10 \mathrm{~mm} / \mathrm{h}$ by using a large rain dispenser. A compact camera recorded videos at 60 frames per second (fps). The corona current waveform was measured by a digital current measurement system, which is described in detail in [23], and was recorded once per minute.

8

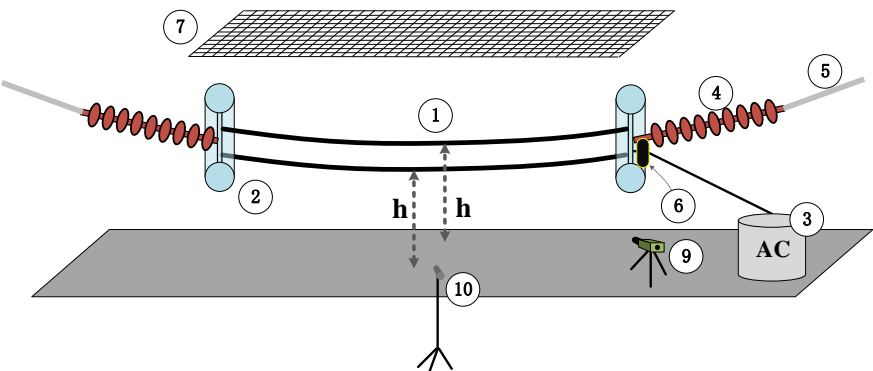

Fig. 1 - Experimental setup. 1 Over head lines, 2 toroid, 3 AC source, 4 insulator, 5 fixed rope, 6 corona current measurement system, 7 mesh, 8 rain dispenser, 9 camera, 10 microphone.

\section{AC CORONA CHARACTERISTICS DURING RAIN}

\section{A. Experimental results}

At the beginning, the rain rate was fixed to $0.5 \mathrm{~mm} / \mathrm{h}$, and the development of audible noise was studied during rain. The transient characteristics of A-weighted audible noise after rain onset is shown in Fig. 2. The audible noise was found heavily dependent on the time duration of rain. Basically, there are three different corona discharge stages throughout the whole rainfall process. The rain started at the moment $\mathrm{T}=10$ minutes, and before that the conductors were clean and dry. As marked in Fig. 2 , the total curve can be separated into four parts. The first part is $\mathrm{T}<10$ minutes (Stage 0 ), in which there is no corona and the dominance of audible noise is the background noise with the Aweighted SPL of around $30 \mathrm{~dB}(\mathrm{~A})$. The second part is the time instants between $\mathrm{T}=10$ minutes and $\mathrm{T}=35$ minutes (Stage 1 ), in which the A-weighted SPL is around $35.5 \mathrm{~dB}(\mathrm{~A})$ and relatively unchanged, a little bit higher than the background noise. The third part is the time instants between $\mathrm{T}=35$ minutes and $\mathrm{T}=80$ minutes (Stage 2 ), in which the A-weighted SPL increases gradually from $36 \mathrm{~dB}(\mathrm{~A})$ to $52 \mathrm{~dB}(\mathrm{~A})$. The fourth part is for $\mathrm{T}>80$ minutes (Stage 3 ), in which the A-weighted SPL is constant at $52 \mathrm{~dB}(\mathrm{~A})$, much higher than the level in Stage 1. Besides, there are four time instants a, b, c, d marked in Fig. 2, which are corresponding to the times of the captured UV snapshots in Fig. 3. The UV characteristics are quite different under distinct stages. As shown in Fig. 3(a), the corona after the rain onset (stage 1) occurs on the upper side of the conductor or faces to the side. In stage 2, there are corona sources on both upper side and lower side of the conductor, and the number of corona discharge points increases with the rain duration, as shown in Fig. 3 (b) and Fig. 3(c). In stage 3, the number of 
corona discharge points is very similar to the end of stage 2 , as illustrated in Fig. 3(c) and Fig. 3(d). The measured corona current patterns and corresponding nominalized voltage waveform are shown in Fig. 4, and the corresponding parameters of corona current is shown in Table I. It is important to point out that the amplitude of normalized voltage waveform in this figure is irrelevant to the applied voltage, and only the phase information is used for reference. The time instants in Fig 4 (a), (b), (c), and (d) relate to the times in both Fig. 2 and Fig. 3. Compared to the positive corona current pulses, the corona current pulses generated in the negative part of the AC cycle are characterized by very low amplitudes, therefore the audible noise is mostly caused by the positive part of the AC cycle, even though the negative pulses might be much higher in number, which is demonstrated in the previous study [21][24]. Thus, in this paper, the main focus of corona current is the corona current pulse generated in positive AC cycle. At the very beginning of rain in stage 1 , the sparser current pulse patterns are detected as shown in Fig. 4 (a) with very low pulse repetition rate (PRR). With rain time, much more corona current pulses are observed in stage 2, as shown in Fig. 4(b), Fig. 4 (c) and the following Table 1. Finally, the number of corona current pulses keeps relatively constant in stage 3 (Fig. 4 (d) and Table 1).

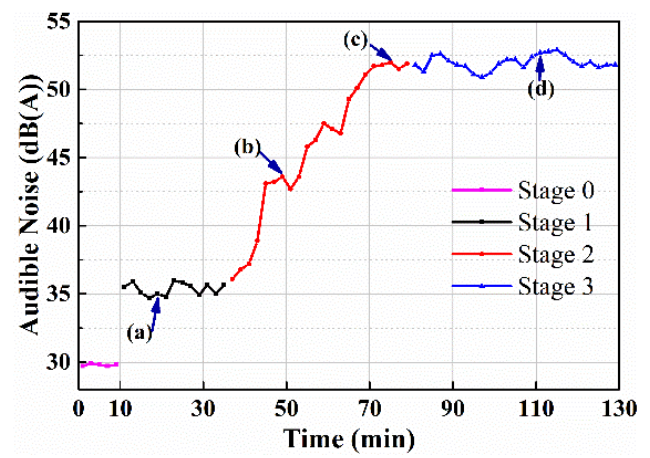

Fig. 2. Audible noise measurement for an applied voltage is $177 \mathrm{kV}$ (25 kV/cm maximum surface field strength) and $0.2 \mathrm{~mm} / \mathrm{h}$ of rain
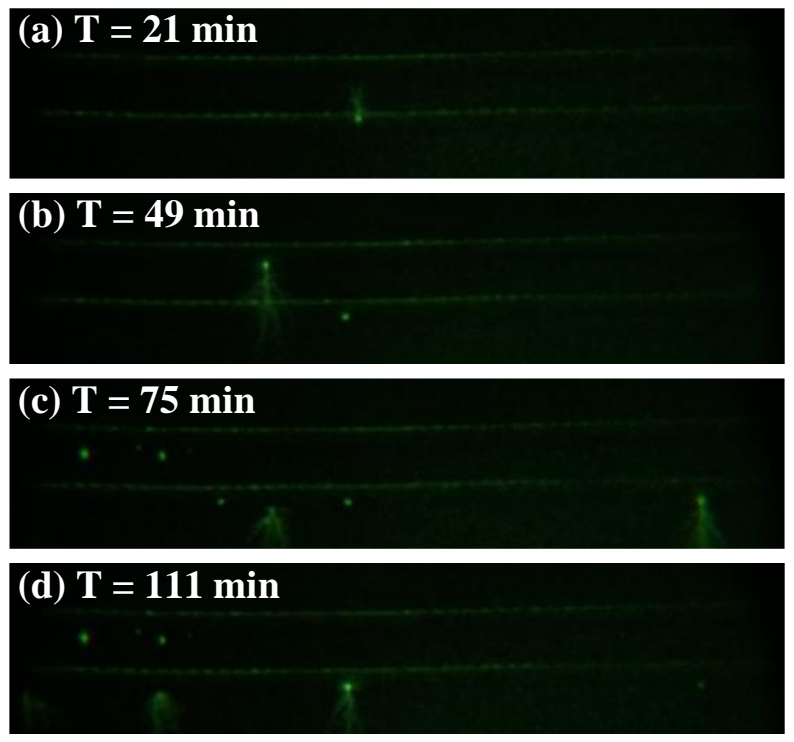

Fig. 3. Corona discharge observation through a UV camera at different times for the measurement shown in Fig. 2
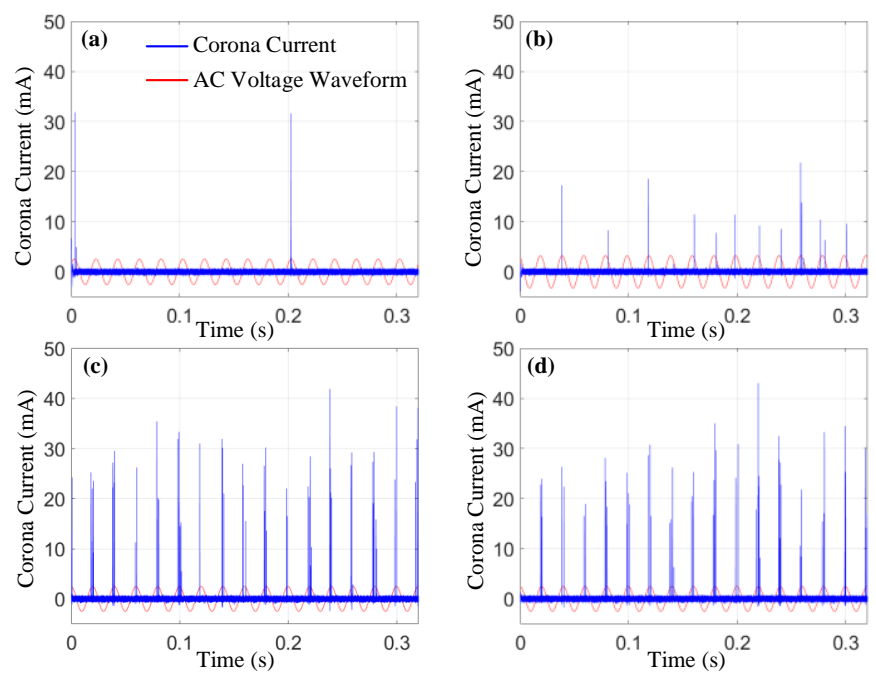

Fig. 4. Corona current patterns and the corresponding normalized voltage waveform.

Table 1. Parameters of corona current pulse and $A N$

\begin{tabular}{ccccc}
\hline \multirow{2}{*}{ Parameters } & \multicolumn{4}{c}{ Time moment } \\
\cline { 2 - 5 } & $\mathrm{a}$ & $\mathrm{b}$ & $\mathrm{c}$ & $\mathrm{d}$ \\
\hline Average pulse amplitude $(\mathrm{mA})$ & 21.6 & 16.8 & 22.2 & 23.7 \\
\hline Max pulse amplitude $(\mathrm{mA})$ & 31 & 23 & 42 & 44 \\
\hline Corona pulse rise time $(\mathrm{ns})$ & 81 & 82 & 79 & 84 \\
\hline Corona pulse last time $(\mathrm{ns})$ & 413 & 420 & 416 & 407 \\
\hline PRR $(\mathrm{Hz})$ & 14 & 95 & 188 & 193 \\
\hline A-weighted SPL $(\mathrm{dB}(\mathrm{A}))$ & 35.1 & 43.0 & 51.8 & 52.6 \\
\hline
\end{tabular}

\section{B. Discussion}

The measured results of the audible noise can be explained by an increasing number of water drops on the conductor and thus corona sources with time. After rain onset, the first drops reach the conductor surface within a couple of seconds. However, the drops move slowly in the grooves of the stranded conductor until reaching the bottom of the conductor [13], [18]. The water distribution on the conductor reaches a steady state after a certain time, when the number of drops vanishing due to the effect of electric field force, gravity and evaporation equals the water collected by conductor surface under rain. The status and distribution of water droplets on the conductor is the key factor to explain the transient audible noise characteristics shown in Fig. 2. The three stages of the audible noise can clearly be attributed to different corona behavior from corona occurring above or below the conductor. As soon as the drops reach the lower side of the conductor, the corona noise increases with the number of drops reaching the lower side. After more than half an hour, steady state is reached and corona occurs exclusively on the lower side of the conductor. Therefore, corona above and below the conductor seems to be dominated by two very different corona mechanisms. For DC corona, it was found that steady state corona is caused by Taylor cones forming on the lower side if the water supply is sufficient. Shortly after rain onset, however, pure corona can be caused by small undeformed drops, causing higher pulses and audible noise compared to the Taylor cones [13]. These discharges have, however, not yet been observed for AC corona. For AC corona, 
recent results from some of the authors [21] revealed that two additional modes are possible. If the water supply was sufficiently high, it was shown that Taylor cones become unstable and do no longer cause significant corona. Instead, they were found to be replaced by the so-called dripping and crashing discharges. In detail, the dripping discharge was detected on the falling water drop just before reaching the upperside of the conductor surface. The crashing discharge initiates as the water drop separates from the lower conductor side. Both these discharge types were observed between falling water drops and the conductor. It was shown that the crashing discharges caused significantly higher pulse amplitudes and therefore also increased audible noise levels. As shown in Fig. 2 , the audible noise jumps from the background level just after the rain onset in stage 1 , and then increases gradually until a steady state level is reached. As mentioned before, the phenomena shown above raise the conclusion that there are two types of corona contributing to the audible noise. As high-speed footage is not available for this setup, it was not possible to determine the exact location of the discharge. During stage 1, the corona discharge happens exclusively on the upper side of the conductor as illustrated in Fig. 3(a). There was simply not enough time for water drops to accumulate at the lower side of conductor surface. During the entire period of stage 1, the average pulse amplitude and pulse repetition rate remain approximately constant and similar to the values shown in Table 1. As the rain rate is quite stable during the whole rainfall process, the dripping discharge [21] intensity caused by rainfall should remain the same and could explain why the audible noise level during stage 1 remains unchanged as shown in Fig. 2. This is supported by analyzing the corona current pulse patterns. With increasing rain duration, large water drops form also on the lower side of the conductors, allowing discharges to occur also there, as illustrated in Fig. 3 (b). The optical data does not allow to clearly show which type of discharge forms (Taylor cones or dripping discharge), but it clearly shows that the discharge happens on the lower side of the conductor. More and more drops forming on the lower side lead to more corona discharges and higher audible noise level, as demonstrated in Fig. 2 and Fig. 3(c). The number of corona current pulse increases accordingly. Finally, the droplet distribution on the conductor reaches a relative equilibrium under certain rain rate and applied AC voltage, thus the audible noise keeps the same in stage 3 (Fig. 2 \& Fig. 3 (d)). The corona current parameters also reach a relative equilibrium as shown in Table 1.

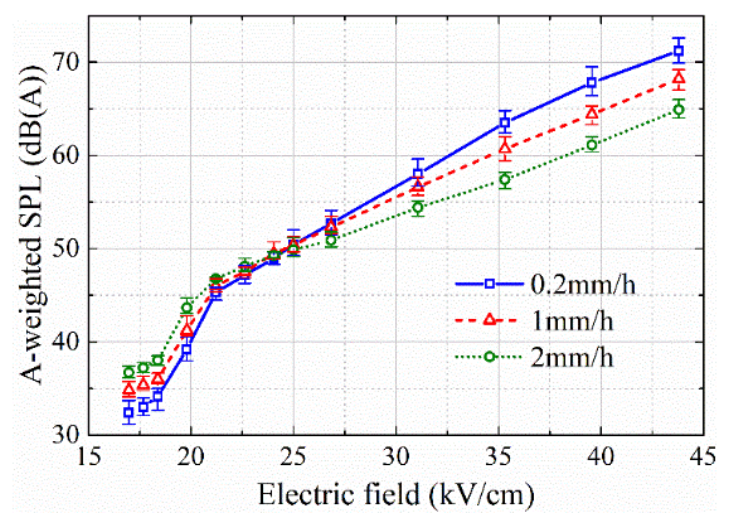

Fig. 5. Influence of electric field and rain rate on steady state AN.

\section{INFLUENCE OF RAIN RATE AND SURFACE GRADIENT}

\section{A. Experimental results}

In the previous part, the transient $\mathrm{AC}$ corona characteristics during rain is observed and discussed. It is obvious that the audible noise generally increases during rain and finally, a relative equilibrium is reached and the audible noise also keeps constant after time (c) in Fig. 2. This constant audible noise is defined as the steady state audible noise, which is also the maximum audible noise level reached during rain for $\mathrm{AC}$ corona. Therefore in the following part, the main focus is the characteristics of audible noise under steady state, on which the influence of rain rate as well as surface gradient will be discussed further.

The measured steady state audible noise under different rain rates and applied electric fields are illustrated in

Fig. 5. There is a clear trend that the audible noise increases with the increasing applied electric field in the range of $17-44 \mathrm{kV} / \mathrm{cm}$. However, the influence of rain rate on audible noise is different compared to the previous understanding. If the electric field is smaller than approximately $25 \mathrm{kV} / \mathrm{cm}$, the audible noise increases with the increase of rain rate, which is in accordance with the previous studies [8]-[11]. But this trend is reversed when the applied electric field increases to values larger than 25 $\mathrm{kV} / \mathrm{cm}$, where the audible noise decreases with the increase of rain rate. Moreover, the influence of rain rate as well as applied electric field on audible noise level seems to be nonlinear. The increase in audible noise with rain rate is weakened gradually with the increase of electric field. For surface gradients around $25 \mathrm{kV} / \mathrm{cm}$, there is almost no measurable difference between the different rain rates. For fields above $25 \mathrm{kV} / \mathrm{cm}$, the audible noise was actually found to decrease with increasing rain rate.

The corona current waveforms are illustrated in Fig. 6 and the detailed characteristics of the corona current are listed in Table 2. With increasing electric field and rain rate, the corona pulse repetition rate (PRR) increases correspondingly. However, the average pulse amplitude differs under different applied electric fields and rain rates. When the applied electric field equals to $18.4 \mathrm{kV} / \mathrm{cm}$, the pulse amplitude almost keeps constant as the rain rate varies from $0.2 \mathrm{~mm} / \mathrm{h}$ to $2 \mathrm{~mm} / \mathrm{h}$. Over an applied electric field of $25 \mathrm{kV} / \mathrm{cm}$, the average pulse amplitude decreases gradually with increasing rain rate. As the electric field further increases to $35.4 \mathrm{kV} / \mathrm{cm}$ and $43.8 \mathrm{kV} / \mathrm{cm}$, the trend that the average pulse amplitude decreases with the increase of rain rate becomes more significant. The attenuation rates of pulse amplitude as the rain rate increases from 0.2 to $2 \mathrm{~mm} / \mathrm{h}$ are $55 \%$ when the applied electric field is $35.4 \mathrm{kV} / \mathrm{cm}$ and $60 \%$ when the applied electric field is $43.8 \mathrm{kV} / \mathrm{cm}$. Besides, the transition time, which describes the time from rain onset until a steady state is firstly reached. The steady state is represented by the mean value of the almost constant audible noise level as shown in Fig. 2 (d), was observed to increase with increasing electric field and decreasing rain rate.

In the following, the one-third octave bands of audible noise are used to study the influence of rain rate on audible noise, which are illustrated in Fig. 7 to Fig. 10. As shown in Fig. 8, the most significant difference between the audible noise and background noise lies in the frequency band ranging above $50 \mathrm{~Hz}$. Therefore, this paper will only focus on the one-third octave bands above $50 \mathrm{~Hz}$. With the applied electric field of 
$18.4 \mathrm{kV} / \mathrm{cm}$, the one-third octave bands under different rain rates basically show a similar spectrum. However, the amplitude is obviously larger under a higher rain rate than that with lower rain rate. This phenomenon is in accordance with the results of Fig. 7 as the A-weighted SPL increases with the increase of rain rate under the applied electric field of $18.4 \mathrm{kV} / \mathrm{cm}$. Moreover, there are four main peaks above $50 \mathrm{~Hz}$, located at $100 \mathrm{~Hz}$, nearly $200 \mathrm{~Hz}, 2 \mathrm{kHz}$, and $16 \mathrm{kHz}$.

For an electric field of $25 \mathrm{kV} / \mathrm{cm}$, as shown in Fig. 8, the trend of the amplitudes differs. It is apparent that in the frequency range of $100 \mathrm{~Hz}$ to $1 \mathrm{kHz}$, the amplitude is in positive correlation with the rain rate, especially for the tonal $2 f$ component at $100 \mathrm{~Hz}$. But as the frequency goes higher than $4 \mathrm{kHz}$, the highest amplitude occurs under the rain rate of $1 \mathrm{~mm} / \mathrm{h}$, while the lowest amplitude is found with the rain rate of $2 \mathrm{~mm} / \mathrm{h}$. There are also four main peaks in the bands, located at $100 \mathrm{~Hz}, 200 \mathrm{~Hz}, 2 \mathrm{kHz}$, and $16 \mathrm{kHz}$. But for the peaks located at $100 \mathrm{~Hz}$ and $200 \mathrm{~Hz}$, the amplitude is largest for $2 \mathrm{~mm} / \mathrm{h}$ and decreasing with rain rate. In contrast, for the peaks located at $8 \sim 20 \mathrm{kHz}$, the amplitude is lowest for the highest rain rate of $2 \mathrm{~mm} / \mathrm{h}$.
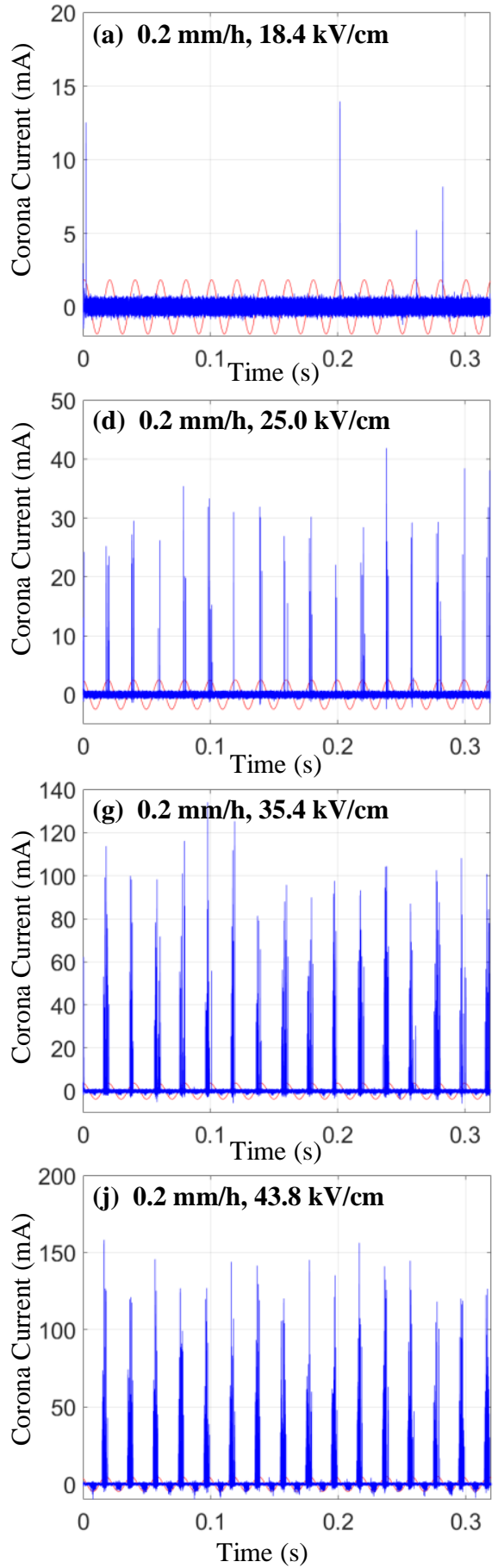
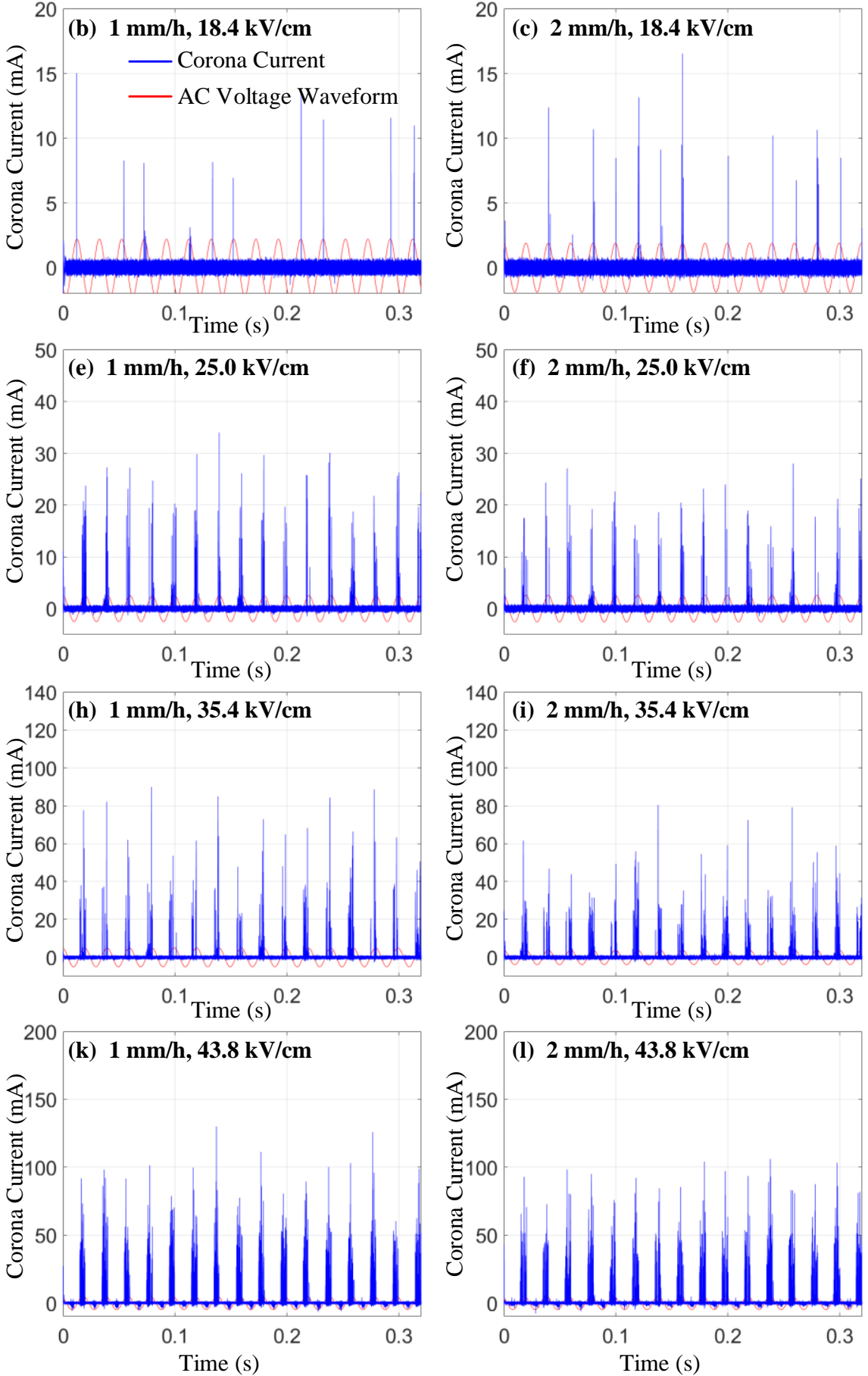
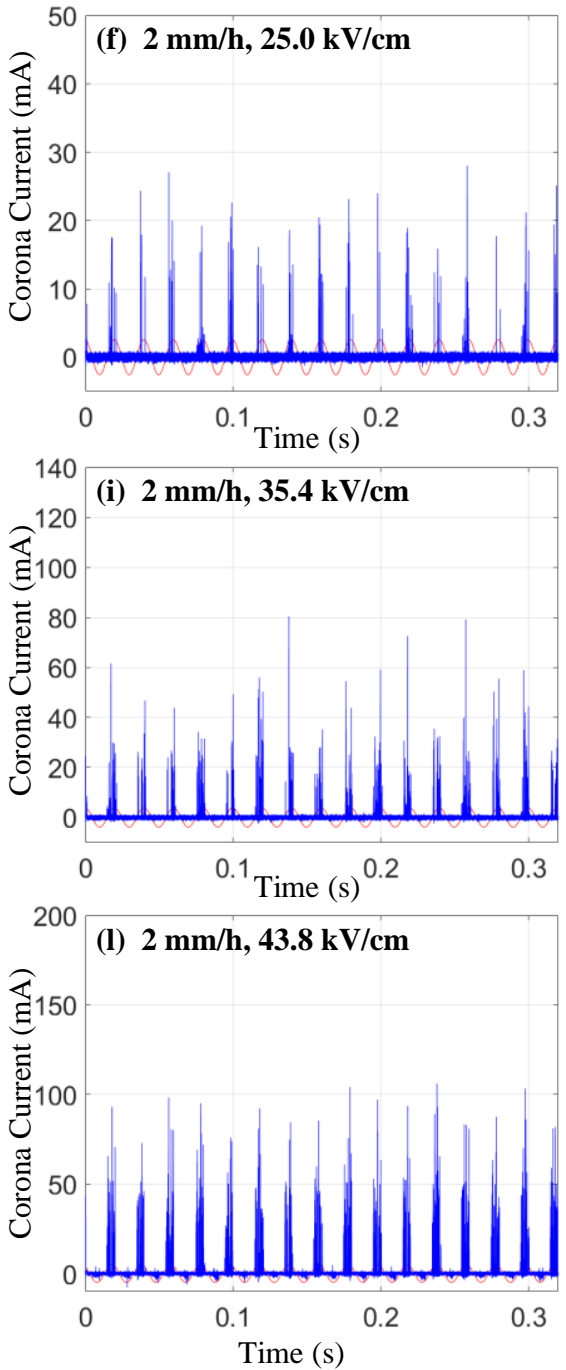

Fig. 6. Corona current waveform under different applied electric fields and rain rates. Figure legends $0.2,1,2 \mathrm{~mm} / \mathrm{h}$ means the corresponding rain rates, and 18.4,25.0,35.4,43.8 kV/cm means the corresponding applied electric field. 
As the applied voltage further increases to $35.4 \mathrm{kV} / \mathrm{cm}$ and $43.8 \mathrm{kV} / \mathrm{cm}$, the one-third octave bands with different rain rates are shown in Fig. 9 and Fig. 10. In these two figures, within the frequency range from $100 \mathrm{~Hz}$ to $200 \mathrm{~Hz}$, basically the amplitude increases with increasing rain rate. However, with the frequency ranging from $1 \mathrm{kHz}$ to $20 \mathrm{kHz}$, the amplitude decreases with increasing rain rate. Two evident peaks are located at $100 \mathrm{~Hz}$ and $400 \mathrm{~Hz}$. And the frequency spectrum curves between $1 \mathrm{kHz}$ and $20 \mathrm{kHz}$ are relatively flat compared to that of the situation under $18.4 \mathrm{kV} / \mathrm{cm}$ and $25 \mathrm{kV} / \mathrm{cm}$.

Table 2. Parameters of the steady state current pulses and AN

\begin{tabular}{|c|c|c|c|c|c|c|}
\hline $\begin{array}{c}\text { Electric } \\
\text { field } \\
\mathrm{kV} / \mathrm{cm}\end{array}$ & $\begin{array}{c}\text { Rain } \\
\text { rate } \\
\mathrm{mm} / \\
\mathrm{h}\end{array}$ & $\begin{array}{l}\text { Avg. } \\
\text { Pulse } \\
\text { ampli } \\
\text {-tude } \\
\text { (mA) }\end{array}$ & $\begin{array}{c}\text { Max } \\
\text { pulse } \\
\text { ampli } \\
\text {-tude } \\
\text { (mA) }\end{array}$ & $\begin{array}{l}\text { PPR } \\
(\mathrm{Hz})\end{array}$ & $\begin{array}{c}\text { A- } \\
\text { Level } \\
\text { SPL } \\
\text { dB(A) }\end{array}$ & $\begin{array}{c}\text { Tran- } \\
\text { sition } \\
\text { time } \\
\text { (min) }\end{array}$ \\
\hline \multirow{3}{*}{18.4} & 0.2 & 9.8 & 14 & 18 & 32.9 & 55 \\
\hline & 1 & 10.1 & 15 & 58 & 35.5 & 25 \\
\hline & 2 & 9.3 & 17 & 117 & 38.2 & 10 \\
\hline \multirow{3}{*}{25} & 0.2 & 20.8 & 43 & 179 & 50.7 & 70 \\
\hline & 1 & 19.5 & 35 & 351 & 50.9 & 30 \\
\hline & 2 & 17.2 & 28 & 675 & 50.6 & 15 \\
\hline \multirow{3}{*}{35.4} & 0.2 & 38.5 & 134 & 669 & 63.3 & 90 \\
\hline & 1 & 21.3 & 92 & 2381 & 61.5 & 70 \\
\hline & 2 & 17.9 & 81 & 3757 & 57.3 & 25 \\
\hline \multirow{3}{*}{43.8} & 0.2 & 45.7 & 163 & 1728 & 71.1 & 115 \\
\hline & 1 & 28.2 & 131 & 4478 & 68.4 & 95 \\
\hline & 2 & 19.1 & 109 & 6234 & 64.3 & 40 \\
\hline
\end{tabular}

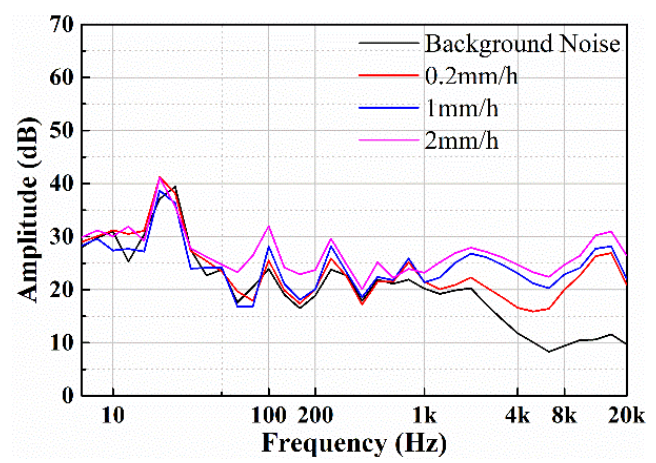

Fig. 7. Influence of rain rate on audible noise one-third octave bands when the electric field is $18.4 \mathrm{kV} / \mathrm{cm}$.

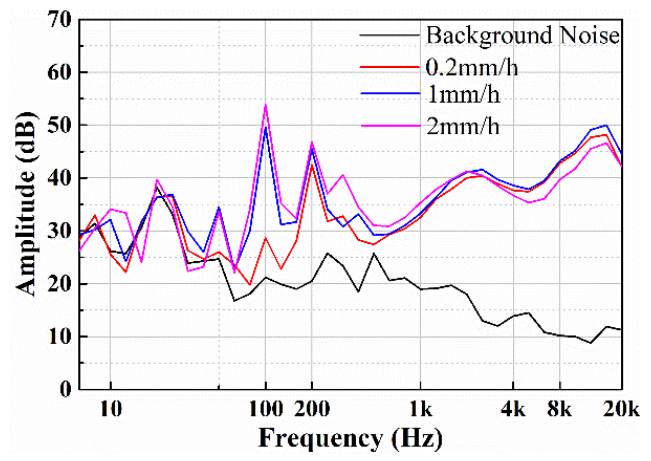

Fig. 8. Influence of rain rate on audible noise one-third octave bands when the electric field is $25 \mathrm{kV} / \mathrm{cm}$.

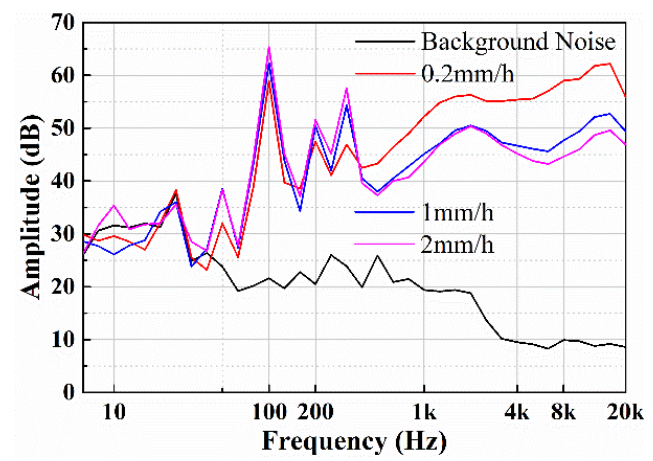

Fig. 9. Influence of rain rate on audible noise one-third octave bands when the electric field is $35.4 \mathrm{kV} / \mathrm{cm}$.

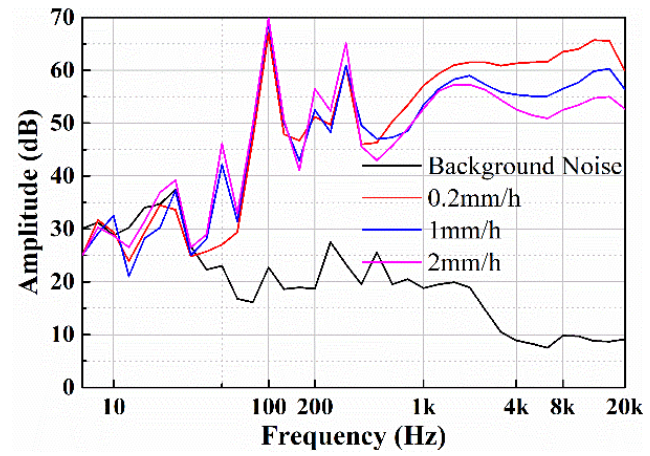

Fig. 10. Influence of rain rate on audible noise one-third octave bands when the electric field is $43.8 \mathrm{kV} / \mathrm{cm}$.

\section{B. Discussion}

The findings of influence of rain rate and surface gradient on audible noise largely deviate from the previous understanding of AC corona characteristics under rain [8]-[11] when the electric field increases to more than $25 \mathrm{kV} / \mathrm{cm}$. The main finding in this part is that the audible noise increases with the rain rate when the applied electric field is lower than $25 \mathrm{kV} / \mathrm{cm}$, which is in agreement with literature [3]. However, the tendency is different under applied electric fields larger than $25 \mathrm{kV} / \mathrm{cm}$. A simple explanation lies in the current pulse amplitude and repetition rate as shown in Table 2. As illustrated in Ref. [13], [18] by Straumann, the acoustic energy caused by a single current pulse will always exceed the energy-equivalent addition of two pulses of exactly half its energy. Therefore, single pulses of high amplitude will have a relatively larger influence on the audible noise level compared to a high number of pulses of low amplitude. In this paper, with the collective effect of pulse amplitude and pulse repetition rate, the audible noise also presents different tendencies under distinct applied electric fields as well as the rain rates. At the beginning, when the electric field is $18.4 \mathrm{kV} / \mathrm{cm}$, the A-weighted SPL increases with the enhancement of rain rate, because both the pulse amplitude and repetition rate increase with the increase of rain rate. When the electric field increases to $25 \mathrm{kV} / \mathrm{cm}$, the pulse amplitude decreases a little bit and at the same time, the repetition rate increases with the increase of rain rate, resulting in an almost constant A-weighted SPL, which indicates that the current pulse amplitude plays a more import role in the determination of the audible noise level. As the electric field 
increases further to $35.4 \mathrm{kV} / \mathrm{cm}$ and $43.8 \mathrm{kV} / \mathrm{cm}$, with the increase of rain rate, the obviously decreasing pulse amplitude leads to a decrease of A-weighted SPL, even though the repetition rate increases rapidly. The corona current pulse pattern is of vital importance to understand the distinct phenomena, especially as the electric field exceeds $25 \mathrm{kV} / \mathrm{cm}$, but the generation of the corresponding current pattern needs reasonable explanation too. One possible explanation can be attribute to the concept of "critical number of corona sources" [18]. The meaning of this concept is that if the number or density of corona sources exceeds a certain level, the space charges created by the discharge will shield adjacent corona sources and therefore reduce their corona intensity. It is important to point out that this concept is typically used for DC corona as the space charge can accumulate to a higher level and in this way significantly influence the background electric field. For AC corona it is assumed that the space charge is lower than that of the DC corona under the same condition and thus the effect of space charges is reduced. However, the previous conclusion is mostly based on experimental results for typical surface gradients usually lower than $25 \mathrm{kV} / \mathrm{cm}$. If the applied electric field reaches a considerably high level and at the same time the number of water drops and generated space charge in one AC half-wave is large enough, the "critical number of corona sources" could possibly be exceeded. As possible evidence for the concept of "critical number of corona sources", long-exposure photos under different surface electric fields and rain rates during steady state are used.
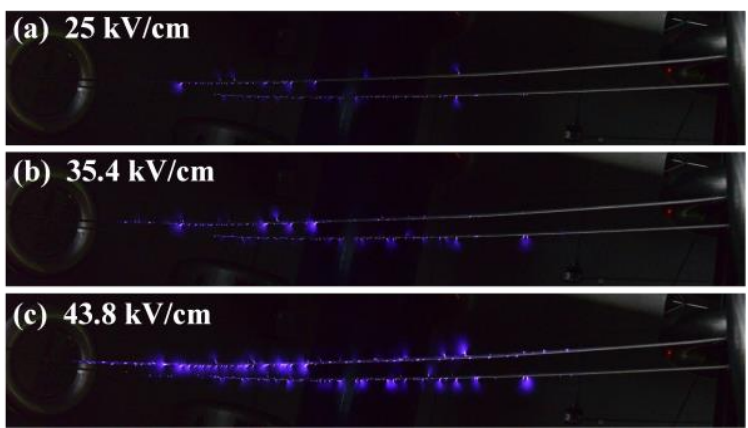

Fig. 11. AC corona under long-exposure photos with different applied electric field when rain rate is $0.2 \mathrm{~mm} / \mathrm{h}$.
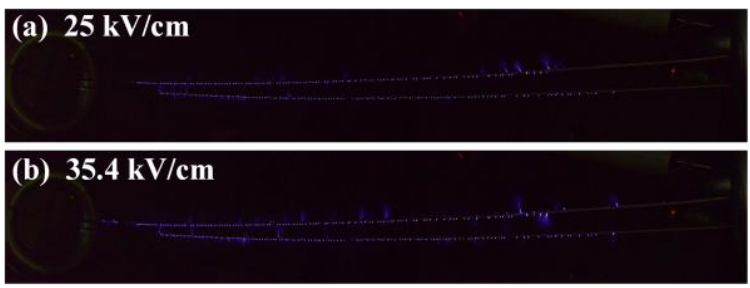

(c) $43.8 \mathrm{kV} / \mathrm{cm}$

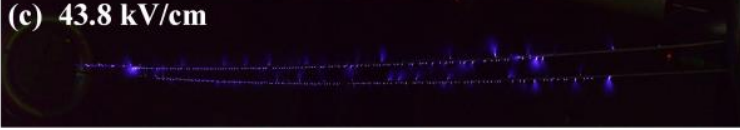

Fig. 12. AC corona under long-exposure photos with different applied electric field when rain rate is $2 \mathrm{~mm} / \mathrm{h}$.

Although the quality of the optical data does not allow for a quantitative analysis, the qualitative analysis of corona source distribution as well as the intensity of streamers can be obtained. As shown in Fig. 11 and Fig. 12, it can be observed that when the applied electric fields are high enough, for example reaching 35.4 or $43.8 \mathrm{kV} / \mathrm{cm}$, the corona sources with the rain rate of $2 \mathrm{~mm} / \mathrm{h}$ spread all over the conductors, whose density is much higher than that of $0.2 \mathrm{~mm} / \mathrm{h}$. Meanwhile, the brightness of a single corona source under rain rate of $0.2 \mathrm{~mm} / \mathrm{h}$ is obviously brighter compared to that of $2 \mathrm{~mm} / \mathrm{h}$. This phenomenon can be regarded as possible evidence for the concept of "critical number of corona sources" on AC corona under heavy rain. Another possible explanation and contribution to the decrease of audible noise with rain rate under high electric fields is based on the occurrence of so-called "pure corona" on small undeformed drops as discussed in [13]. As this type of discharge is shown to occur on small drops for DC fields, especially with higher gradients, this type could also occur for AC voltage. As pure corona usually requires higher electric fields and typically causes strong low frequent pulses, this is a possible explanation why AC audible noise is higher for high electric fields. At the same time, it was shown that this kind of discharge is suppressed for the case of DC corona, after the conductor has accumulated enough water to form Taylor cones on the lower side of the conductor. Therefore, it could be possible that pure corona forms at high surface gradients but cannot occur for higher rain rates, as the formation of small drops is no longer possible.

\section{CONCLUSION}

In this paper, a more precise and stable rain simulator was used to investigate the influence of rain rate on $\mathrm{AC}$ corona. The development of AC audible noise and corona current pulse characteristics under rainfall condition were studied and explained. It was found that there are three stages of audible noise during rain in which the steady state shows the highest noise levels. This transient characteristic of the AC audible noise was found to be caused by different corona types from discharges above or below the conductor. This phenomenon could possibly be explained based on the recently published concept of two different corona discharge types from water drops, namely dripping and crashing discharge. Furthermore, the steady state audible noise was studied under a high range of rain rate and applied surface electric field. It was demonstrated that the sensitivity of the audible noise level to the rain rate decreases with the applied electric field and actually turns negative for high surface gradients. As a result, the audible noise increases with increasing rain rate when the electric field is lower than $25 \mathrm{kV} / \mathrm{cm}$, and the audible noise decreases with the increase of rain rate for electric fields above $25 \mathrm{kV} / \mathrm{cm}$.

One reasonable explanation for this phenomenon is attributed to "critical number of corona sources". The main idea of this concept is when the number or density of corona sources exceeds a certain level, the space charges created within the discharge will shield adjacent corona sources and therefore reduce their corona intensity. Although this concept is typically used for DC corona, however, under the condition of rain and high electric AC field, there is a large number of corona sources and it is possible that the space charge initiated in half of the $\mathrm{AC}$ electric cycle would satisfy the requirement of "critical number of corona sources". The long-exposure photos for high electric fields with different rain rates indicate that the single corona intensity with fewer corona sources is apparently larger than that with more corona sources. This can be regarded as possible evidence for the existence of a "critical number of 
corona sources", even for AC corona. Furthermore, as the Alevel audible noise at high electric fields was higher for fewer corona sources, this shows the importance of the higher energy of single pulses compared to a high repetition rate. These findings strongly contribute to the research of AC corona audible noise during rain of various intensities. The observed effects will be further investigated on a newly built outdoor setup [25]. Furthermore, the presented data clearly shows that the prevalent rain rates should be considered when predicting corona audible noise. Utilities should be aware that existing models to incorporate the rain rate do not account for the influence of the electric field on the rain rate dependency. Therefore, empirical formulas might predict too high noise levels for high rain rates and surface gradients, but could also underestimate the rain effect for low electric fields, which is important due to that some older towers or converted towers with restricted geometry in Europe might have high surface gradients, if the tower is upgraded to a higher voltage but the height remains the same.

\section{REFERENCES}

[1] S. Hedtke, M. Pfeiffer, C. M. Franck, C. Dermont, I. Stadelmann-Steffen, and J. Jullier, "HVDC \& hybrid HVAC/HVDC overhead line conversion: An acceptance case study," in Cigre Session, Paris, 2018.

[2] P. S. Maruvada, Corona in Transmission Systems: Theory, Design and Performance. Crown Publications, 2011.

[3] J. J. LaForest, M. G. Comber, and L. E. Zaffanella, Transmission Line Reference Book: $345 \mathrm{kV}$ and Above 2nd Edition. 1982.

[4] M. Akazaki, "Corona Phenomena from Water Drops on Smooth Conductors under High Direct Voltage," IEEE Trans. Power Appar. Syst., vol. 84, no. 1, 1965.

[5] U. Straumann, "Mechanism of the tonal emission from ac high voltage overhead transmission lines," J. Phys. D. Appl. Phys., vol. 44, no. 7, p. 075501, Feb. 2011.

[6] CIGRE Working Group 36.01, "Technical Brochure 61: Interferences produced by corona effects of electric systems," 1974.

[7] V. L. Chartier and R. D. Stearns, "Formulas for Predicting Audible Noise from Overhead High Voltage AC and DC Lines," IEEE Trans. Power Appar. Syst., vol. PAS-100, no. 1, pp. 121-130, 1981.

[8] M. G. Comber and R. J. Nigbor, "Audible noise performance of the first three-phase ultra-high voltage transmission test line at EPRI's Project UHV," IEEE Trans. Power Syst., vol. PAS-95, no. 4, pp. 25-30, 1976.

[9] H. Kirkham, "The Influence of Rain Rate on Transmission Line Corona Performance," IEEE Trans. Power Appar. Syst., vol. PAS-100, no. 1, pp. 420-430, Jan. 1981.

[10] J. Lundquist, "Results from AC transmission line audible noise studies at the Anneberg EHV test station," IEEE Trans. Power Deliv., vol. 5, no. 1, pp. 317-323, 1990.

[11] L. Chen, D. Yu, X. Bian, L. Wang, and Z. Guan, "Influence of different rain rates on AC corona discharge with corona cage." 2012.
[12] S. Hedtke, M. Pfeiffer, C. M. Franck, L. Zaffanella, J. Chan, and J. Bell, "Audible noise of hybrid AC / DC overhead lines : Comparison of different prediction methods and conductor arrangements," in EPRI's High-Voltage Direct Current \& Flexible AC Transmission Systems Conference, 2015.

[13] M. Pfeiffer, T. Schultz, S. Hedtke, and C. M. Franck, "Explaining the impact of conductor surface type on wet weather HVDC corona characteristics," $J$. Electrostat., vol. 79, pp. 45-55, 2016.

[14] U. Schichler et al., "Test-run for uprating a $220 \mathrm{kV}$ OHL to $380 \mathrm{kV}$ using insulated cross-arms and coated conductors," in Cigre Session, Paris, 2016, pp. B2301.

[15] F. Ianna, G. Wilson, and D. Bosack, "Spectral Characteristics of Acoustic Noise from Metallic Protrusions and Water Droplets in High Electric Fields," IEEE Trans. Power Appar. Syst., vol. PAS93, no. 6, pp. 1787-1796, Nov. 1974.

[16] S. Hedtke, M. Pfeiffer, A. Gaillard, and C. M. Franck, "Effect of electrostatic induction and space charges on the audible corona noise of hybrid AC/DC transmission lines," in CIGRE-IEC Colloquium on EHV and $U H V(A C \& D C), 2016$.

[17] G. I. Taylor, "Disintegration of Water Drops in an Electric Field," Proc. R. Soc. A Math. Phys. Eng. Sci., vol. 280, no. 1382, pp. 383-397, Jul. 1964.

[18] L. D. Anzivino et al., HVDC transmission line reference book. EPRI, 1993.

[19] M. Pfeiffer and C. M. Franck, "Impact of Conductor Surface Type and Rain Intensity on HVDC Corona Losses," IEEE Trans. Power Deliv., vol. 30, no. 5, pp. 2284-2292, 2015.

[20] P. Xu, B. Zhang, Z. Wang, S. Chen, and J. He, "Dynamic corona characteristics of water droplets on charged conductor surface," J. Phys. D. Appl. Phys., vol. 50, no. 8, 2017.

[21] P. Xu, B. Zhang, Z. Wang, S. Chen, and J. He, "Dynamic characteristics of corona discharge generated under rainfall condition on AC charged conductors," J. Phys. D. Appl. Phys., vol. 50, no. 50, p. 505206, Dec. 2017.

[22] X. Li, J. Wang, Y. Li, Q. Zhang, T. Lu, and X. Cui, "Correlation between audible noise and corona current generated by AC corona discharge in time and frequency domains," Phys. Plasmas, vol. 25, no. 6, p. 063512, Jun. 2018.

[23] H. Yin, B. Zhang, J. He, and W. Wang, "Measurement of positive direct current corona pulse in coaxial wirecylinder gap," Phys. Plasmas, vol. 21, no. 3, p. 032116 , Mar. 2014.

[24] N. G. Trinh, "Particle Discharge XIX: Discharge in Air Part 1: Physical Mechanisms," Ieee Electr. Insul. Mag., vol. 11, no. 2, pp. 23-29, 1995.

[25] S. Hedtke, M. Pfeiffer, M. Gobeli, P. Bleuler, R. Bräunlich, and C. M. Franck, "Setup of an outdoor hybrid AC / DC test line for corona measurements," in VDE High Voltage Congress, 2018. 